\title{
ANÁLISE DA RESISTÊNCIA AO DESGASTE DE REVESTIMENTO DURO APLICADO POR SOLDAGEM EM FACAS PICADORAS DE CANA-DE-AÇÚCAR
}

\author{
(ANALYSIS OF WEAR RESISTANCE OF HARDFACING APPLIED BY WELDING IN SUGARCANE SHREDDER \\ KNIFE.)
}

\author{
Aldemi Coelho Lima ${ }^{1}$, Valtair Antonio Ferraresi ${ }^{2}$ \\ ${ }^{1}$ Instituto Federal de Educação, Ciência e Tecnologia de Goiás - IFG, Goiânia, Goiás, Brasil \\ e-mail:acl@ifgo.edu.br \\ ${ }^{2}$ Universidade Federal de Uberlândia, UFU, Faculdade de Engenharia Mecânica, Uberlândia, MG, Brasil, valtairf@mecanica.ufu.br
}

\begin{abstract}
Resumo
O setor sucroalcooleiro brasileiro tem apresentado um expressivo crescimento nos últimos anos, entretanto, a manutenção das indústrias apresenta um elevado custo devido à perda de metal dos equipamentos por mecanismos de desgaste. O objetivo deste trabalho é estudar a aplicação de revestimentos duros por soldagem com arames tubulares quanto à resistência ao desgaste de facas picadoras de cana-de-açúcar, comparando os resultados obtidos em laboratórios com os aplicados em campos. Foram utilizados quatro tipos de consumíveis utilizados na indústria sucroalcooleira: um eletrodo revestido da liga $\mathrm{FeCrC}$ de 4,0 mm de diâmetro e três arames tubulares autoprotegidos de 1,6 mm de diâmetro, de ligas Fe-23,1Cr-4,11C, Fe-22Cr-4,5C-6,5Nb, Fe-1,8C-7,5Cr-1,5Mo-5,26Ti. O metal de base utilizado foi um aço SAE 1020. Foram construídos corpos de prova para a avaliação de desgaste em laboratório com abrasômetro Roda de Borracha segundo a norma ASTM G65-91. Posteriormente, foram construídas facas picadoras de cana-de-açúcar, revestidas com as mesmas condições de soldagem e montadas no picador de uma destilaria de álcool. A avaliação de desgaste foi feita via perda de massa. As soldagens com os arames tubulares foram efetuadas no modo de transferência por curto-circuito, com mesmos valores de corrente e tensão de soldagem. $\mathrm{O}$ arame contendo $\mathrm{Nb}$ apresentou a maior resistência ao desgaste em laboratório e devido à presença de trincas e ao lascamento do revestimento, a menor resistência ao desgaste em campo. O arame $\mathrm{FeCrC} \mathrm{e} \mathrm{o} \mathrm{arame} \mathrm{contendo} \mathrm{Ti} \mathrm{e} \mathrm{Mo}$ apresentaram resistência ao desgaste similar, com o pior desempenho em laboratório e o melhor em campo. Comparados ao eletrodo revestido, apenas o arame contendo $\mathrm{Nb}$ apresentou similar desempenho em laboratório e o arame $\mathrm{FeCrC}$ e o arame com adição de $\mathrm{Ti}$ e Mo, similar desempenho em campo.
\end{abstract}

Palavras-chaves: Arame tubular autoprotegido, Revestimento duro, Setor sucroalcooleiro, Resistência ao desgaste.

Abstract: The Brazilian sugar/alcohol sector presented expressive growth in recent years. However maintenance cost is high due to metallic losses by wear. This paper studies the application of hardfacings by flux cored arc welding on the wear resistance of sugarcane shredder knives comparing laboratory and field-test results. Four types of consumable were used: three selfshielded flux cored wires of diameter $1.6 \mathrm{~mm}$ of alloys $\mathrm{FeCrC}, \mathrm{FeCrC}+\mathrm{Nb}$ and $\mathrm{Fe} \mathrm{CrC}+\mathrm{Ti}$ and a covered electrode of $\mathrm{Fe} \mathrm{CrC}$ alloy of diameter $4.0 \mathrm{~mm}$. The base metal is SAE 1020 steel. Test specimens were evaluated using rubber wheel abrasion tests (ASTM G65). Sugarcane shredder knives hardfaced in the same welding conditions were also tested on a shredder in an alcohol distillery. Wear evaluation is by mass loss. The flux cored wires were welded in short-circuit transfer mode with the same current and voltage values. The wire with $\mathrm{Nb}$ had the highest wear resistance in laboratory test but due to cracks and spalling had the least wear resistance in field test. $\mathrm{The} \mathrm{FeCrC} \mathrm{and} \mathrm{FeCrC}+\mathrm{Ti}$ wires presented the worst results in laboratory tests and the best results in field test, respectively. In comparison with the covered electrode, the $\mathrm{FeCrC}+\mathrm{Nb}$ wire presented similar performance in laboratory and the $\mathrm{FeCrC}+\mathrm{Ti}$ wire presented similar performance in field tests

Keywords: Hardfacing, Wear resistance, Flux cored wire, Sugar/alcohol industries.

\section{Introdução}

O setor sucroalcooleiro brasileiro vem apresentando grande expansão nos últimos anos em função do aumento de consumo

(Recebido em 06/11/2009; Texto final em 24/05/2010). Artigo originalmente publicado no CONSOLDA 2009, Piracicaba, SP, Outubro de 2009. do etanol no mercado interno e externo. A elevada capacidade produtiva com custos competitivos do setor sucroalcooleiro brasileiro, frente ao etanol de milho (americano) e ao de beterraba ou mandioca, além da grande quantidade de terra disponível para o cultivo da cana colocam o Brasil numa condição de liderança no mercado mundial do etanol e do açúcar. Por sua vez, a perda de material por mecanismos de desgaste representa um custo significativo para a operação de usinas de açúcar e destilarias de álcool, onde a deterioração das ferramentas é grande e a vida em 
serviço dos componentes é curta [1].

A redução da capacidade produtiva ocorre devido às paradas constantes para a substituição das peças desgastadas, bem como, pelos custos de recuperação das mesmas, envolvendo mão-de-obra, equipamentos e consumíveis de soldagem, dentre outros. Novas técnicas de soldagem e novos tipos de consumíveis (eletrodos) têm sido desenvolvidos para minimizar esses problemas. A aplicação de revestimentos com o objetivo de reduzir o desgaste e, consequentemente os custos, busca o incremento da vida em serviço dos componentes e na redução das paradas para manutenção. Uma correta seleção do material depositado permite (dentre outras coisas) transformar elementos descartáveis por desgaste em bens de capital recuperável, aumentar a resistência e prover as superfícies susceptíveis ao desgaste de características e propriedades desejadas e, em geral, aumentar a eficiência do processo em que tomam parte os elementos reconstruídos e/ou protegidos.

As facas picadoras, seguidas pelos martelos desfibradores, são as primeiras ferramentas a entrarem em contato com a cana-de-açúcar durante a preparação desta para a extração do caldo. Têm a função de cortar e desfibrar as células da mesma para possibilitar a maior eficiência na extração da sacarose nas moendas, estágio seguinte. Para aumentar a resistência ao desgaste, as ferramentas, geralmente construídas em aço carbono 1020 recebem a aplicação de uma camada de revestimento duro nas faces que entram em contato direto com a cana.

$\mathrm{O}$ desgaste acentuado dessas ferramentas se deve à elevada velocidade de impacto com a cana, na presença de elementos agressivos como areia, pedaços de madeira, raízes, pedras e ferro que são coletados durante o processo de carregamento. Além disso, acredita-se que fatores como a variedade da cana, a abrasividade do solo de cultivo, o método de colheita (manual ou mecanizada), a qualidade da lavagem da cana, dentre outros, possam ter influência relevante no volume de perda de massa das ferramentas [1].

O desgaste progressivo das facas picadoras e dos martelos desfibradores é responsável pela redução da eficiência na extração da sacarose, o que leva à realização das paradas programadas com o objetivo de realizar a sua substituição. Durante essas paradas, toda a produção é interrompida por um período de 8 a 12 horas, ocasionando uma significativa perda de produção, além do envolvimento de profissionais, materiais, ferramentas, equipamentos e consumíveis para a recuperação e substituição das ferramentas. Essas ferramentas são recuperadas por soldagem pela aplicação de revestimentos duros, utilizandose diferentes processos, técnicas e consumíveis para a reposição do metal desgastado em serviço [1].
Tradicionalmente, a aplicação de revestimentos duros pelo setor industrial brasileiro tem sido feita manualmente com o processo Eletrodo Revestido ou de forma automática com o processo Arco Submerso, quando a geometria ou dimensões da peça se adéquam a essa aplicação. Devido à sua maior produtividade em relação ao primeiro, aliada à maior versatilidade quando comparado ao segundo, o processo Arame Tubular tem se tornado uma alternativa importante, contando com uma grande variedade de consumíveis para diferentes aplicações de revestimentos duros.

Neste trabalho foram utilizados três tipos de arames tubulares autoprotegidos de liga ferro-cromo-carbono indicados pelo próprio fabricante para aplicações no setor sucroalcooleiro, especialmente, em facas e martelos desfibradores. A diferença entre os arames refere-se aos diferentes teores de carbono, cromo, silício e manganês, além da adição de nióbio no segundo e a adição de titânio e molibdênio no terceiro. Além disso, foi utilizado também um eletrodo com o processo Eletrodo Revestido tradicionalmente utilizado pelo setor.

O objetivo deste trabalho é avaliar a resistência ao desgaste abrasivo aplicados por soldagem em ensaio por Roda de Borracha e de forma comparativa, o desempenho desses consumíveis, em situação real de trabalho, ou seja, na aplicação de revestimento em faca picadora de cana-de-açúcar. Isso foi feito buscando apontar, a partir da identificação das particularidades da operação das facas quanto à resistência ao desgaste dos revestimentos, qual o arame com melhor desempenho em campo e em ensaios realizados em laboratórios em Roda de Borracha.

\section{Materiais e Métodos}

Foi utilizada uma fonte de soldagem eletrônica multiprocesso ajustada para soldar no modo de tensão constante, processo arame tubular e no modo de corrente constante para o processo eletrodo revestido. As soldas foram efetuadas com quatro consumíveis de liga $\mathrm{FeCrC}$, sendo um com eletrodo revestido de diâmetro de 4,0 $\mathrm{mm}$ e três arames tubulares autoprotegidos de $1,6 \mathrm{~mm}$ de diâmetro; os arames tubulares da liga $\mathrm{FeCrC}$ diferem entre si pelos teores de ferro, cromo, carbono, silício e manganês, além da adição de $\mathrm{Nb}$ em uma liga e da adição de Ti e Mo em outra. Doravante os consumíveis serão denominados, respectivamente, de $\mathrm{FeCrC},+\mathrm{Nb},+\mathrm{Ti}$ e ER1. A Tabela 1 apresenta a faixa de dureza a ser obtida pelo metal de solda em primeira camada, bem como, a composição típica dos arames, cujos dados foram obtidos do fabricante.

Para os ensaios com Roda de Borracha (norma ASTM G6591 [2]) a soldagem foi efetuada em camada única, com cordões

Tabela 1. Dados dos consumíveis (arames tubulares e eletrodo revestido).

\begin{tabular}{|c|c|c|c|c|c|c|c|c|c|c|}
\hline \multirow{2}{*}{ Tipo de eletrodo } & \multirow{2}{*}{ Dureza HRc } & \multicolumn{10}{|c|}{ Composição química (\%) } \\
\cline { 3 - 11 } & & $\mathrm{C}$ & $\mathrm{Cr}$ & $\mathrm{Mn}$ & $\mathrm{Si}$ & $\mathrm{S}$ & $\mathrm{P}$ & $\mathrm{Nb}$ & $\mathrm{Mo}$ & $\mathrm{Ti}$ \\
\hline $\mathrm{FeCrC}$ & $59-61$ & 4,110 & 23,100 & 0,520 & 0,200 & 0,000 & 0,000 & - & - & - \\
\hline $\mathrm{FeCrC}+\mathrm{Nb}$ & $57-64$ & 4,500 & 22,000 & 0,500 & 0,600 & 0,002 & 0,001 & 6,500 & - & - \\
\hline $\mathrm{FeCrC}+\mathrm{Ti}$ & $52-64$ & 1,800 & 7,500 & 0,840 & 0,500 & 0,018 & 0,027 & - & 1,500 & 5,260 \\
\hline $\mathrm{ER} 1$ & $58-63$ & 5,100 & 44,00 & 0,750 & 1,250 & 0,025 & 0,035 & - & - & - \\
\hline
\end{tabular}


Tabela 2. Parâmetros de soldagem para confecção dos corpos de prova para ensaio de desgaste.

\begin{tabular}{|c|c|c|c|c|c|c|c|}
\hline Tipo de Arame & $\begin{array}{l}\text { Diâm } \\
(\mathrm{mm})\end{array}$ & $\begin{array}{c}\mathrm{V}_{\text {alim }} \\
(\mathrm{m} / \mathrm{min})\end{array}$ & $\begin{array}{c}V_{\text {sold }} \\
(\mathrm{cm} / \mathrm{min})\end{array}$ & $\begin{array}{r}\mathrm{U}_{\mathrm{r}} \\
(\mathrm{V}) \\
\end{array}$ & $\begin{array}{c}\mathrm{P} \\
(\mathrm{mm})\end{array}$ & $\begin{array}{l}\mathrm{DBCP} \\
(\mathrm{mm})\end{array}$ & $\begin{array}{r}\mathrm{I}_{\mathrm{m}} \\
(\mathrm{A})\end{array}$ \\
\hline $\mathrm{FeCrC}$ & \multirow{3}{*}{1,6} & \multirow{3}{*}{10} & \multirow{3}{*}{50} & \multirow{3}{*}{28} & 6 & 35 & 270 \\
\hline $\mathrm{FeCrC}+\mathrm{Nb}$ & & & & & 6 & 30 & 270 \\
\hline $\mathrm{FeCrC}+\mathrm{Ti}$ & & & & & 7 & 32 & 270 \\
\hline ER1 & 4 & - & 15 & 40 & 6 & - & 170 \\
\hline
\end{tabular}

Onde: $\mathrm{I}_{\mathrm{m}}=$ corrente média dos cordão de solda; $\mathrm{P}=$ passo de soldagem, ou a distância entre centros de cordões adjacentes.

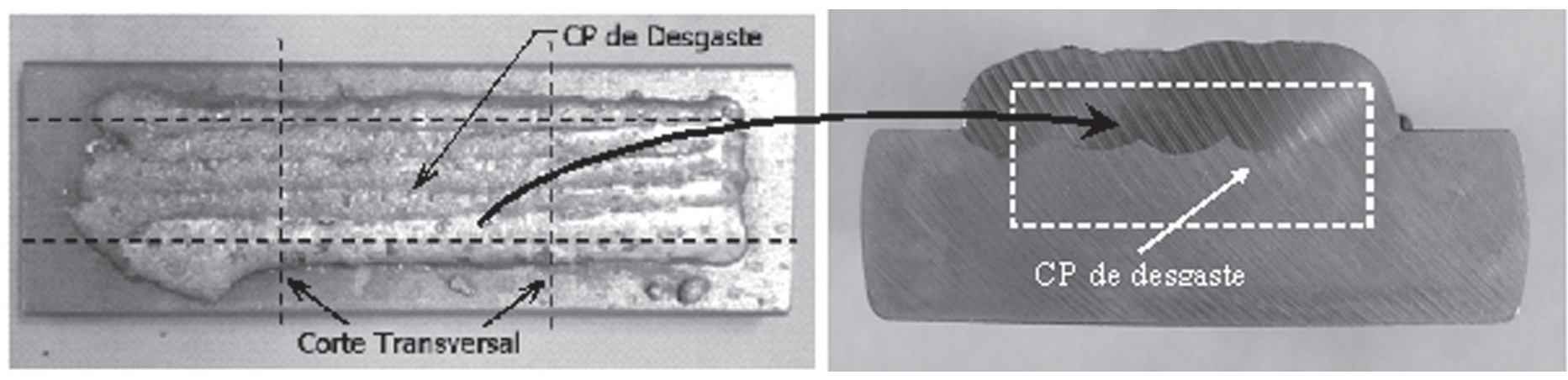

Figura 1. Chapa de testes e região de extração dos corpos de prova (CP de desgaste) para avaliação de desgaste de dimensões $10 \mathrm{x}$ $25 \times 55 \mathrm{~mm}$.

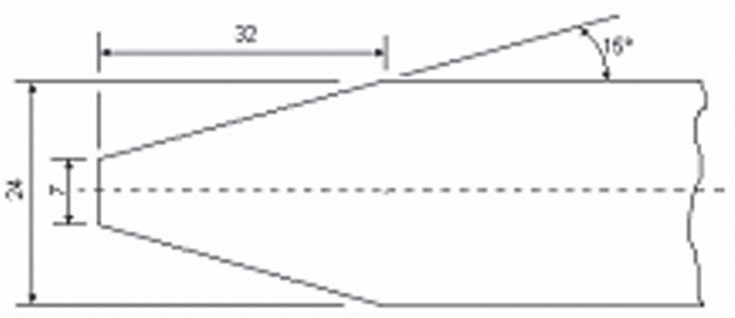

(a)

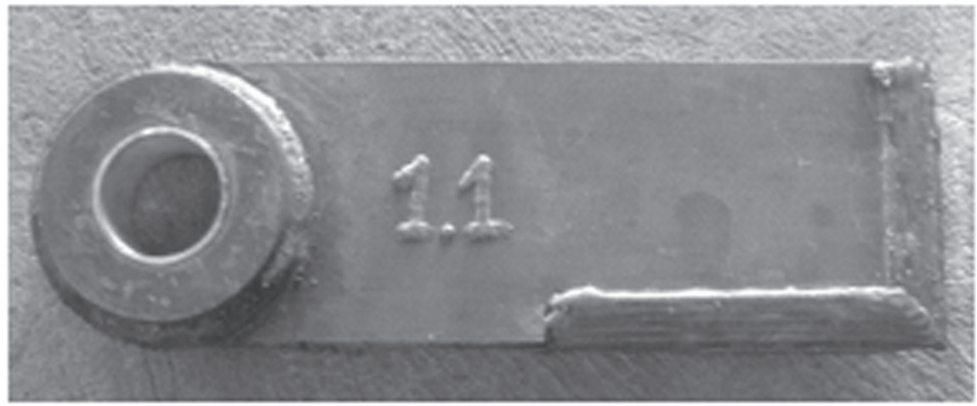

(b)

Figura 2. Vista de uma Faca Picadora. (a) Perfil e dimensões do bisel. (unidade mm); (b) Detalhe de uma faca após aplicação do revestimento de dimensões de 24 x 180 x $580 \mathrm{~mm}$.

de $150 \mathrm{~mm}$ de comprimento (cinco cordões para o revestimento) em chapas de aço SAE 1020 de 12,7 x 50,8 x 200mm (Fig. 1a). Com cada tipo de eletrodo foram soldadas cinco chapas e, da região central das mesmas foram extraídos os corpos de prova (CPs) para a avaliação de desgaste. A Tabela 2 apresenta os parâmetros de soldagem utilizados. Para o processo arame tubular a indutância de subida e descida, a velocidade de alimentação do arame $\left(\mathrm{V}_{\text {alim }}\right)$, a velocidade de soldagem $\left(\mathrm{V}_{\text {sold }}\right)$ e a tensão de referência $\left(U_{r}\right)$ foram mantidas constantes, em condições que proporcionaram a transferência metálica no modo de curto-circuito.

As condições de soldagem foram obtidas de trabalhos anteriores de Lima e Ferraresi [3], com os respectivos arames. A distância bico de contato-peça (DBCP) foi variada com vistas à obtenção de mesma corrente de soldagem para taxa de fusão constante (mesma $\mathrm{V}_{\text {alim}}$ ), já que nessas condições quando se utiliza os parâmetros constantes, inclusive a mesma DBCP, a corrente média de soldagem é diferente para cada arame. Esse procedimento foi importante para se avaliar a resistência ao desgaste dos depósitos de solda quando realizados com mesma corrente de soldagem e mesmo volume de metal depositado por comprimento de solda $\left(\mathrm{V}_{\text {alim }}\right.$ e $\mathrm{V}_{\text {sold }}$ constantes). Para o processo eletrodo revestido as condições de soldagem são as mesmas utilizadas na indústria e indicada pelo fabricante do eletrodo.

A Figura 1 apresenta a vista superior de uma chapa de teste revestida, bem como a seção transversal ilustrando a região de retirada dos corpos de prova de desgaste. Os ensaios de desgaste foram realizados utilizando-se um abrasômetro Roda de Borracha, o qual é recomendado para simulação de desgaste abrasivo de baixa tensão, seguindo as orientações da norma ASTM G65-91 [2], dentre as quais se destacam: as dimensões das amostras foram de 10 × 25 x 55 mm; disco de 12,7 x 228 $\mathrm{mm}$; anel de borracha com dureza de 60 Shore A; a areia Normal Brasileira n 100 (0,15mm); rotação do disco de 200 RPM; tempo de ensaio de $10 \mathrm{~min}$ (ensaio tipo A); força nominal de $130 \mathrm{~N}$; a pesagem das amostras, antes e após a soldagem foi 
efetuada em balança eletrônica com resolução de $10^{-5} \mathrm{~g}$. Todas as amostras foram pré-desgastadas por 5 minutos até atingir o regime de desgaste. Para cada tipo de arame foram realizados cinco ensaios.

Para os ensaios em campo (na indústria), foram construídas 12 facas com as condições de soldagem mostrada na Tabela 2 em aço SAE 1020, com dimensões finais de 24 x 180 x $580 \mathrm{~mm}$. As chapas foram cortadas (Figura 2a) para a obtenção da região a ser revestida (região que entra em contato com a cana durante a picagem). A Figura $2 \mathrm{~b}$ mostra a faca depois de revestida com soldagem e pronta para ser montada no picador (cada faca foi revestida com 12 cordões de solda).

As 12 facas deste trabalho, três revestidas com cada um dos quatro consumíveis, foram instaladas para avaliação juntamente com outras 48 facas construídas pela própria destilaria e não avaliadas neste trabalho. As facas instaladas no picador foram numeradas segundo o tipo de consumível e de acordo com a posição de montagem. As facas foram distribuídas entres os seis eixos do picador (cada eixo contêm 10 facas) conforme o esquema ilustrado na Figura 3.

A avaliação de desgaste das facas foi feita pela análise da perda de peso ocorrida durante a operação, comparando-se o peso das facas revestidas, antes do início do trabalho com o peso após o período de trabalho. A resistência ao desgaste foi obtida pela relação inversa da perda de peso ocorrida durante a operação (desgaste da faca) dividido pela distância percorrida pela faca durante o trabalho em campo.

A distância percorrida pela faca é uma variável difícil de obtida, devido à dificuldade em se definir qual a fração do perímetro percorrido pelas facas em que estas efetivamente têm contato com a cana bruta. Verificou-se durante a pesquisa na empresa que a altura de cana que entra na esteira gira em torno de $900 \mathrm{~mm}$, sendo aproximadamente igual à altura do centro do eixo central do picador. Conclui-se, portanto, que a região em que as facas podem manter contato com a cana, desde o instante que atinge a cana bruta até o instante em que se desvencilha do bagaço, equivale a aproximadamente um terço do perímetro do picador (1780 mm), como ilustrado pelo esquema da Figura 3, a qual apresenta detalhe do picador em corte longitudinal. $\mathrm{O}$ arco $\mathrm{AB}$ representa a extensão do contato das facas com a cana em cada giro do picador.

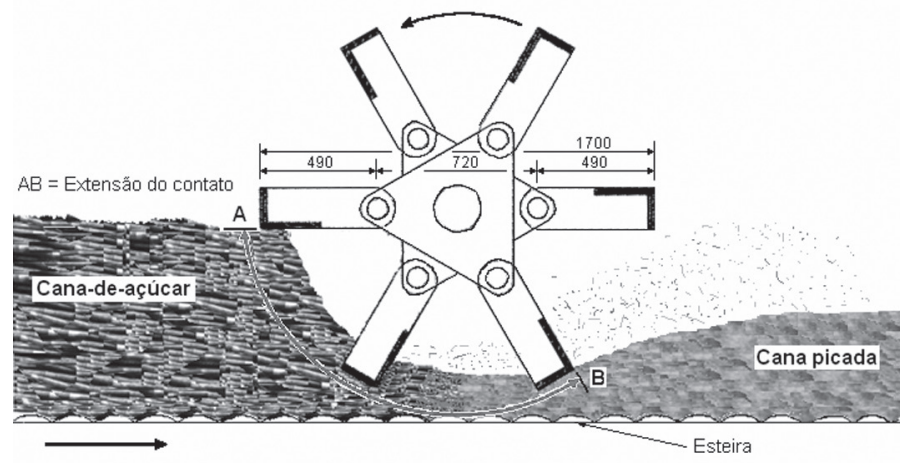

Figura 3. Esquema do picador mostrando a extensão do contato das facas com a cana (unidade $\mathrm{mm}$ ).

\section{Resultados e Discussão}

\subsection{Resistência ao Desgaste em Ensaio Roda de Borracha}

A Figura 4 apresenta os resultados da avaliação em termos de resistência ao desgaste médio por consumível. Observase que dentre os arames tubulares, o melhor resultado (vaores médios) foi obtido pelo arame $+\mathrm{Nb}$, seguido do $+\mathrm{Ti}$ e, com o pior resultado, o arame $\mathrm{FeCrC}$. O eletrodo revestido ER1 proporcionou o segundo melhor resultado geral, dentre todos os consumíveis, com média de perda de massa $26 \%$ superior ao arame $+\mathrm{Nb}$, mas pela sobreposição do desvio padrão, com resultado estatisticamente similar a este.

Buchely et al. [4] avaliou revestimentos depositados com o processo eletrodo revestido de várias ligas contendo ferro, cromo carbono e outros elementos. Verificou-se que a liga rica em $\mathrm{Cr}$ (Liga do tipo $\mathrm{FeCrC}$ ) apresentou maior resistência ao desgaste abrasivo de baixa tensão que a liga rica em carbonetos complexos, como $\mathrm{NbC}, \mathrm{M}_{7} \mathrm{C}_{3}$ e $\mathrm{Mo}_{2} \mathrm{C}$ (liga C-Cr-W-NbMo-V). Esse resultado difere do obtido neste trabalho, onde o revestimento $+\mathrm{Nb}$ foi superior ao $\mathrm{FeCrC}$. Para efeitos de comparação com os resultados de Buchely et al. [4], a resistência ao desgaste dos seus revestimentos variou de 11,2 a 32,3 (mg.m$\left.{ }^{1}\right)^{-1}$, sendo que em uma camada variou de 11,2 a $24,2\left(\mathrm{mg} \cdot \mathrm{m}^{-1}\right)^{-1}$. Neste trabalho, a resistência ao desgaste obtida por revestimento em camada única, variou de 7,69 a 34,48 $\left(\mathrm{mg} \cdot \mathrm{m}^{-1}\right)^{-1}$.

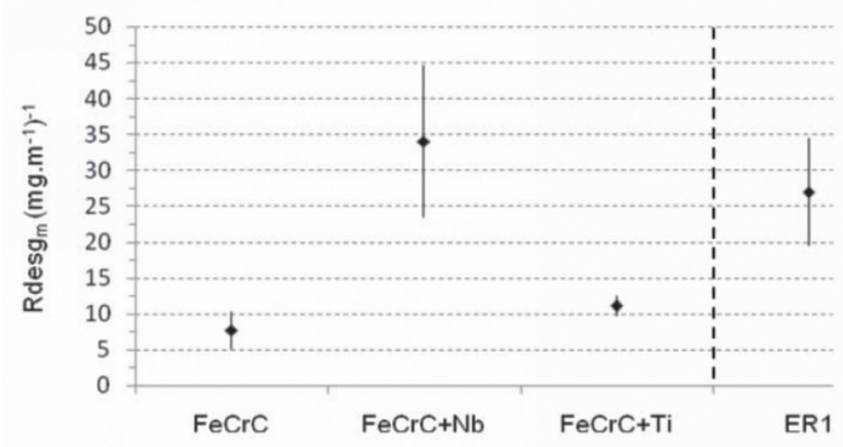

Figura 4. Análise comparativa de resistência ao desgaste por consumível realizado em laboratório com roda de borracha.

Uma comparação entre o trabalho de Buchely et al [4] e o revestimento depositado com o eletrodo revestido deste trabalho mostra que o eletrodo de liga $\mathrm{Fe}-35 \mathrm{Cr}-4,3 \mathrm{C}$ de Buchely et al [4] apresentou resistência ao desgaste na primeira camada de 14,7 (mg. $\left.\mathrm{m}^{-1}\right)^{-1}$, o eletrodo ER1 (Fe-44Cr-5,1C) deste trabalho apresentou resistência média de 27,03 $\left(\mathrm{mg} . \mathrm{m}^{-1}\right)^{-1}$, bem superior, indicando a importância do maior teor de cromo e carbono para aumentar a resistência ao desgaste abrasivo de baixa tensão.

As comparações feitas com o trabalho de Buchely et al [4] mostram que apesar de serem consumíveis diferentes e soldados com condições distintas, resguardadas as devidas proporções, os resultados apresentados neste trabalho estão em acordo com a literatura. Maiores detalhes sobre os ensaios em laboratório e análise da microestrutura podem ser encontrado no artigo de Lima e Ferraresi [3]. 


\subsection{Avaliação de Desempenho em Campo}

Para o ensaio em campo (indústria) a facas foram montadas no picador, conforme citado no item de materiais e métodos. Depois de transcorridos vinte e cinco (25) dias de trabalho e a moagem de cento e trinta e duas mil (132.000) toneladas de cana, as facas dos ensaios em campo (Figura $2 b$ ) foram desmontadas e cuidadosamente limpadas para a remoção de resíduos de cana, material abrasivo e outras sujidades. Em seguida foram pesadas para a obtenção do peso no final do trabalho e consequentemente possibilitarem a determinação da perda de material. A Figura 5 apresenta foto ilustrativa de um exemplar das facas desgastadas após o período de trabalho, com cada consumível, destacando a região de maior desgaste (região de encontro do gume frontal com o gume superior). Essa região (o canto) é a que, durante o trabalho, passa mais próximo à esteira de alimentação da cana, sendo, portanto, mais solicitada devido à velocidade de avanço da esteira ser inferior à velocidade periférica das facas. Nas regiões mais afastadas do canto, tanto no gume frontal, quanto no gume superior, o desgaste é menor e vai progredindo com o tempo de trabalho, principalmente à medida que cresce o desgaste no canto.

Pela Figura 5, verifica-se, além do desgaste por abrasão em todas as facas, a perda de metal por lascamento do revestimento, principalmente nas ferramentas revestidas com os arames $\mathrm{FeCrC}$ $\mathrm{e}+\mathrm{Nb}$. Além disso, verifica-se alguma perda de metal de base nas faces das facas, na região de contato com a cana (superfície lixada das facas na Figura 5) e também perda de pedaços de revestimento nas extremidades de início da solda, nos dois arames citados.

Como a perda de massa foi dimensionada via pesagem das facas, antes e após o período de trabalho, não foi possível separar a perda de metal por abrasão e a perda por lascamentos do revestimento, em alguns casos, a perda mais significativa. A Figura 6 apresenta a perda de peso médio (Desg ${ }_{\mathrm{m}}$ ) das três facas revestidas com cada consumível e do ER1. Verifica-se que, dentre os arames tubulares, que o melhor resultado em valores médios (menor desgaste) foi obtido com o revestimento $+\mathrm{Ti}$, seguido do $\mathrm{FeCrC}$ e, com o maior desgaste, o revestimento $+\mathrm{Nb}$. O eletrodo ER1 apresentou desgaste similar ao revestimento $+\mathrm{T} 1$.

$\mathrm{O}$ maior desgaste do $+\mathrm{Nb}$ ocorreu devido à fratura $\mathrm{e}$ lascamento de parte do revestimento, principalmente na região mais solicitada, pois quando o desgaste vence a camada de revestimento protetor e atinge o metal de base, a taxa de desgaste tende a aumentar progressivamente, devido à menor resistência deste. Com isso, a redução de volume da faca progride mais rapidamente.

Uma provável causa do lascamento de partes de revestimentos frágeis, em região de muitas trincas pode, além do impacto normal com a cana e outros objetos, também estar relacionada com o impacto da faca sobre a própria estrutura do picador. Esses impactos ocorrem durante a partida (aceleração), durante a parada do equipamento (desaceleração) ou após o choque das facas, tanto com a cana, quanto com materiais duros durante o trabalho, pelo fato de as ferramentas girarem livres sobre os eixos. Os choques na região oposta ao gume, aliado ao impacto com a cana e outros objetos estranhos na região frontal

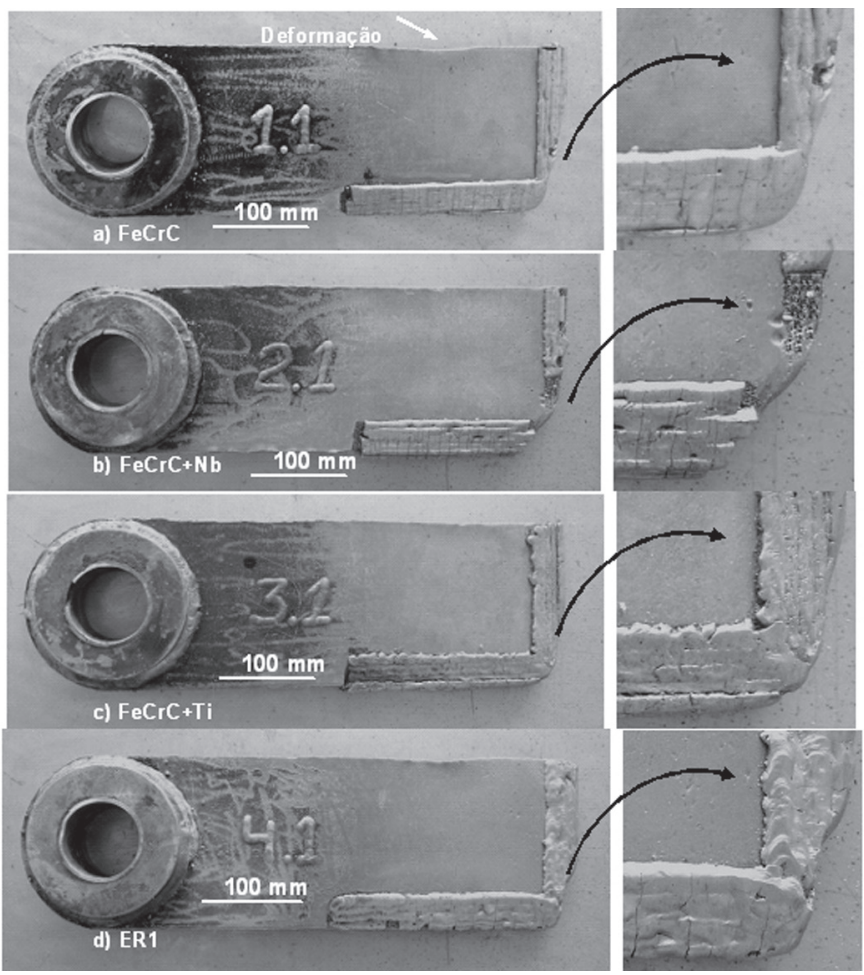

Figura 5. Facas desgastadas, com detalhe do canto de maior desgaste: arame $\mathrm{FeCrC}, \mathrm{FeCrC}+\mathrm{Nb}, \mathrm{FeCrC}+\mathrm{Ti}$ e eletrodo revestido ER1.

(região do gume) podem ser responsáveis pela propagação de trincas, pelo aumento do seu número e, conseqüentemente, pelos destacamentos de partes do revestimento.

Pela análise anterior (destacamento do revestimento), suspeita-se que as condições de soldagem utilizadas não tenham sido as melhores para o arame $\mathrm{FeCrC}$ e para o $+\mathrm{Nb}$, do ponto de vista das tensões geradas durante a soldagem, onde os cordões paralelos tenham favorecido a propagação de trincas e, consequentemente o lascamento do revestimento. Como os arames apresentam composição química diferente, a soldagem com mesmas condições pode não ter sido adequada para a avaliação de cada um no seu ponto ótimo. Em função disso, acredita-se que seja importante a investigação posterior visando a identificação das condições ótimas para cada consumível do ponto de vista do controle de trincas, mas preservando a baixa diluição e elevada produtividade.

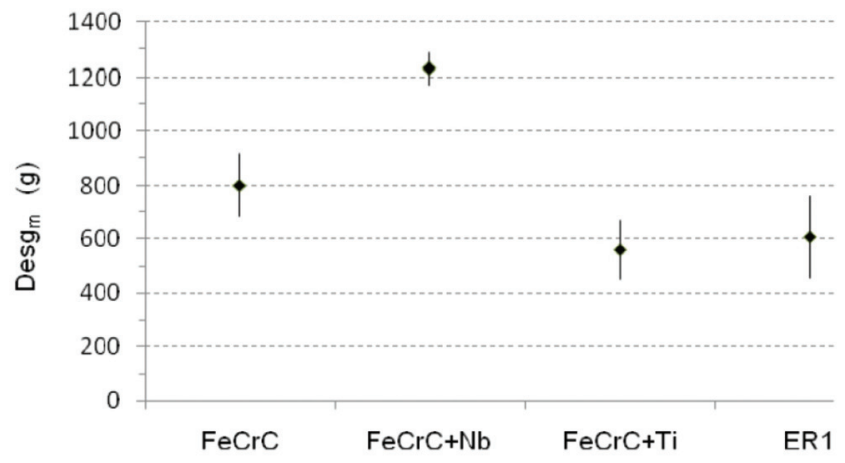

Figura 6. Histograma ilustrando o desgaste das facas por consumíveis realizados em campo. 
Segundo Carceller [5], a adição de Mn nas ligas de revestimento duro objetiva incrementar a sua resistência ao impacto. Apesar do baixo teor de Mn das ligas utilizadas observa-se que os revestimentos que foram mais influenciados pelos lascamentos foram aqueles com menor teor de $\mathrm{Mn}$, casos do $+\mathrm{Nb}$ e do FeCrC. $\mathrm{O}$ eletrodo ER1, que foi o terceiro mais afetado pelos lascamentos, tem o terceiro maior índice de Mn na composição química.

Os valores médios obtidos da resistência ao desgaste pelo ensaio das facas revestidas com os quatro consumíveis, durante essa etapa do trabalho estão ilustrados na Figura 7. A resistência ao desgaste do arame $\mathrm{FeCrC} \mathrm{e}+\mathrm{Ti}$ apresenta maior resistência o desgaste que o $+\mathrm{Nb}$. Comparando o eletrodo ER1 com os arames tubulares verifica-se que este apresentou resistência ao desgaste média $\left(\operatorname{Rdesg}_{\mathrm{m}}\right)$ ligeiramente inferior ao arame $+\mathrm{Ti}$, de melhor desempenho neste quesito, mas superior ao arame $\mathrm{FeCrC} \mathrm{e}+\mathrm{Nb}$, em valores médios.

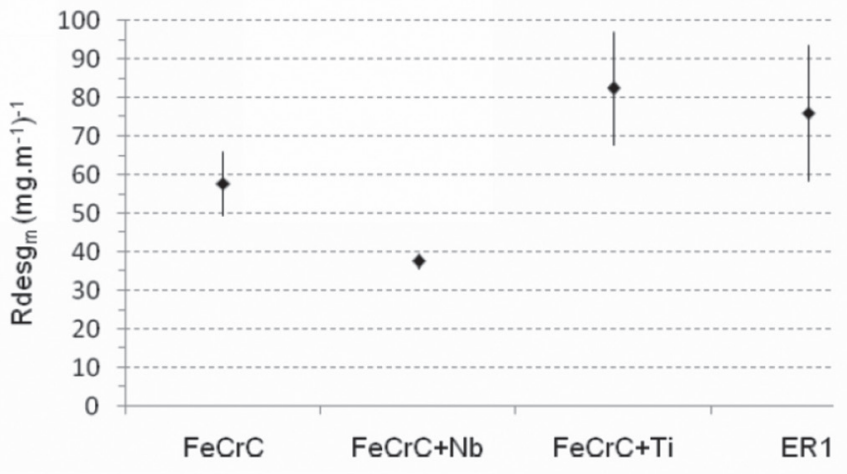

Figura 7. Resistência ao desgaste médio por consumível realizado em campo.

O melhor desempenho em termos de resistência ao desgaste do arame +Ti concorda com Gregory [6], segundo o qual a adição de molibdênio (presente nesse arame) no revestimento duro é importante para aumentar a resistência à abrasão. Além disso, de acordo com Wang et al. [7], o carboneto de titânio (TiC) possui maior dureza e estabilidade que os carbonetos de cromo (CrC), fazendo com que materiais reforçados com TiC tenham cadeias muito fortes, proporcionando melhores propriedades de resistência ao desgaste da liga.

$\mathrm{O}$ pior resultado do arame $+\mathrm{Nb}$, por sua vez, estaria relacionado ao lascamento do revestimento na presença de trincas e sob a ação do impacto com a cana e com a estrutura do picador. Isso contrasta com o melhor resultado do +Ti que não apresentou trincas superficiais visíveis a olho nu, antes ou após o trabalho.

A Figura 8 apresenta detalhe da mesma superfície de uma faca revestida com o arame $\mathrm{FeCrC}$, antes e após o trabalho. É possível verificar por comparação visual à vista desarmada que o tamanho e a quantidade de trincas do revestimento, originadas durante a soldagem e não dimensionadas (Figura 8a), aumentou após o período de trabalho no picador (Figura 8b).
As trincas transversais ao cordão de solda são segundo Wainer, Brandi e De Mello [8], trincas de contração e ocorreriam devido à baixa ductilidade ou, às vezes, ao baixo limite de escoamento do revestimento. Tais trincas aliviam as tensões, são visíveis a olho nu e podem propagar-se com trabalhos mecânicos.

A Figura 9 ilustra detalhes do revestimento dos quatro consumíveis, no gume frontal, próximo ao canto de maior desgaste. Destaca-se na figura, a quantidade de trincas do arame $\mathrm{FeCrC}$ e $+\mathrm{Nb}$, que como conseqüência, provocou no segundo consumível em algumas regiões, uma acentuada fragmentação do revestimento. Além disso, observa-se em região revestida com o eletrodo ER1, além de trincas, o arrancamento de pedaços do revestimento. Contrastando com esses resultados observase praticamente intacto o revestimento efetuado com o arame +Ti. No detalhe da Figura $9 \mathrm{~b}$ pode-se constatar que não ocorreu problema de ligação do metal de solda, mas sim, a fragmentação progressiva do revestimento devido à presença de trincas.

Segundo Scotti e Rosa [9] durante o processo de soldagem podem aparecer trincas devido à fragilidade dos revestimentos duros. Estas não são, necessariamente, indicadores de redução na resistência ao desgaste, podendo até serem favoráveis por reduzirem as tensões internas. Por outro lado, são indesejáveis nos casos de revestimentos estanques ou sob esforços dinâmicos que levem à fadiga e, conseqüentemente, ao arrancamento do revestimento. Por sua vez, Martins Filho [10] cita que para revestimentos de liga $\mathrm{Fe}-\mathrm{Cr}-\mathrm{C}-\mathrm{V}$ aplicados com arames tubulares, a ausência de trincas é decisiva para o aumento da resistência ao desgaste abrasivo.

Corrêa et al [11] afirmam que as ligas Fe-Cr-C são susceptíveis às trincas de solidificação, as quais aliviam as tensões de soldagem, mas, no caso de aplicações onde o componente está sujeito à vibração ou impacto, podem levar à fragmentação do revestimento. Em função disso, se busca incessantemente a obtenção de ligas que apresentem um bom desempenho de resistência ao desgaste e tenacidade.

Acredita-se que a soldagem com condições que minimizem a geração de trincas ou dificultem a sua propagação possa melhorar o desempenho dos dois arames mais afetados por lascamentos, concordando com a conclusão de Martins Filho [10]. Portanto sugere-se que trabalhos posteriores busquem a otimização de técnicas e de parâmetros de soldagem, como oscilação da tocha, ângulo de ataque, corrente, tensão, velocidade de soldagem e distância bico de contato-peça, além de modo de transferência metálica e diluição da solda que minimizem a geração de trincas e, dessa forma, avaliar o desempenho dos arames citados $(\mathrm{FeCrC}$ e $+\mathrm{Nb})$ sob essas condições. Scotti e Rosa [9] mostraram em seu trabalho, com arame tubular de liga Fe-0,5C-5B, que é possível produzir depósitos de revestimento duro livres de trinca, combinando com elevada dureza, pela utilização de pré-aquecimento e de oscilação da tocha.

\subsection{Desgaste em Laboratório x Desgaste em Campo}

A relação entre a resistência ao desgaste em laboratório pela resistência ao desgaste em campo também se mostrou diferente para os quatro consumíveis, denotando o diferente efeito das propriedades do revestimento duro proporcionadas por cada 


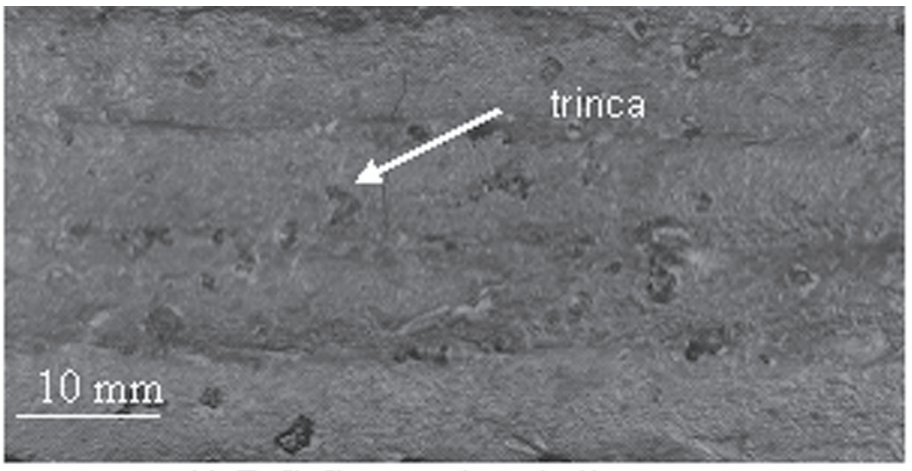

(a) $\mathrm{F} e \mathrm{CrC}$ antes do trabalho em campo

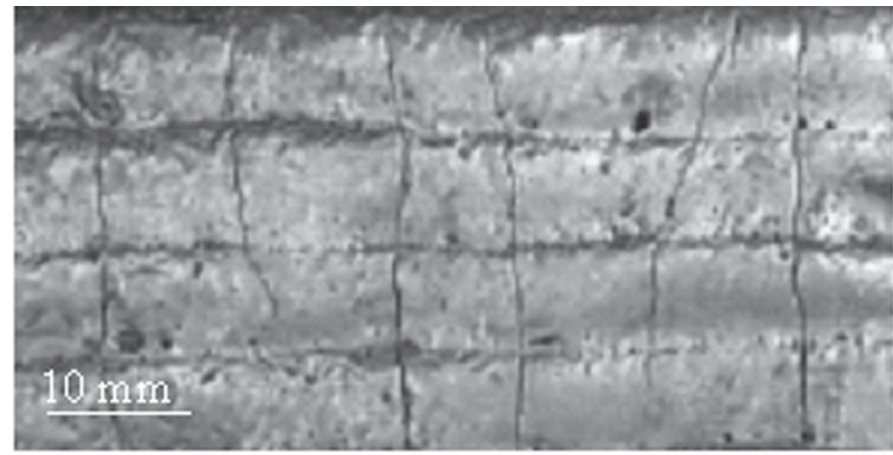

(b) $\mathrm{F}$ eCrC após o trabalho em campo.

Figura 8. Detalhe da superfície revestida de uma mesma faca antes (a) e após o trabalho em campo(b).
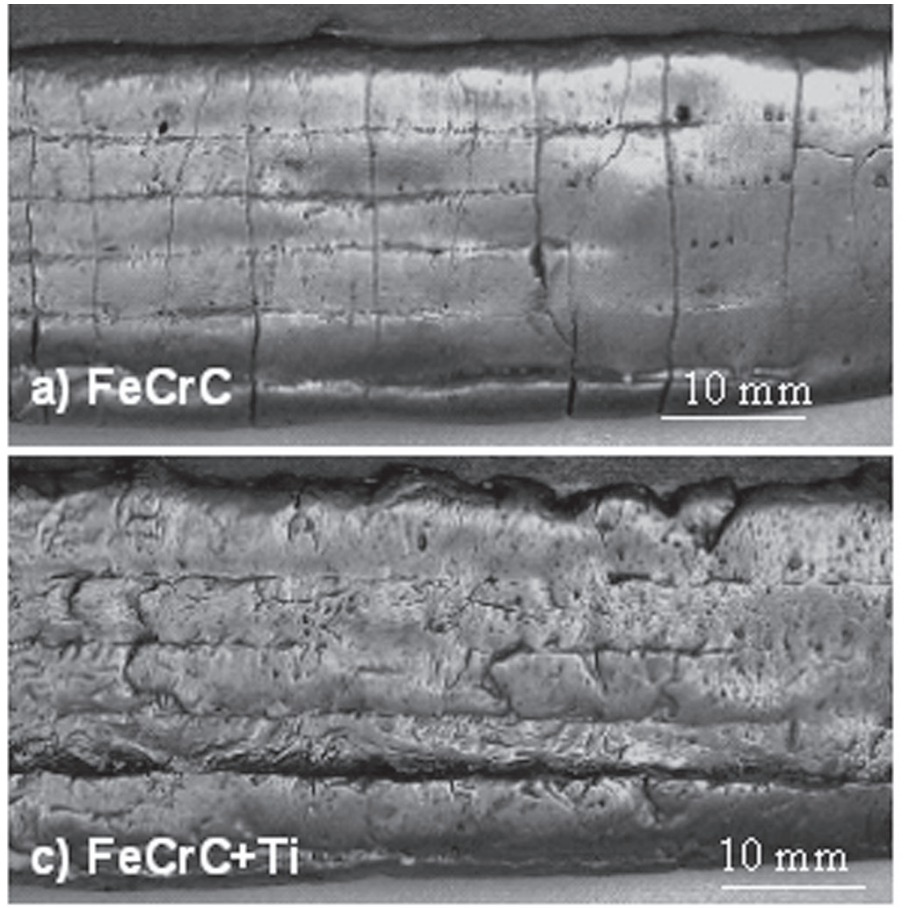

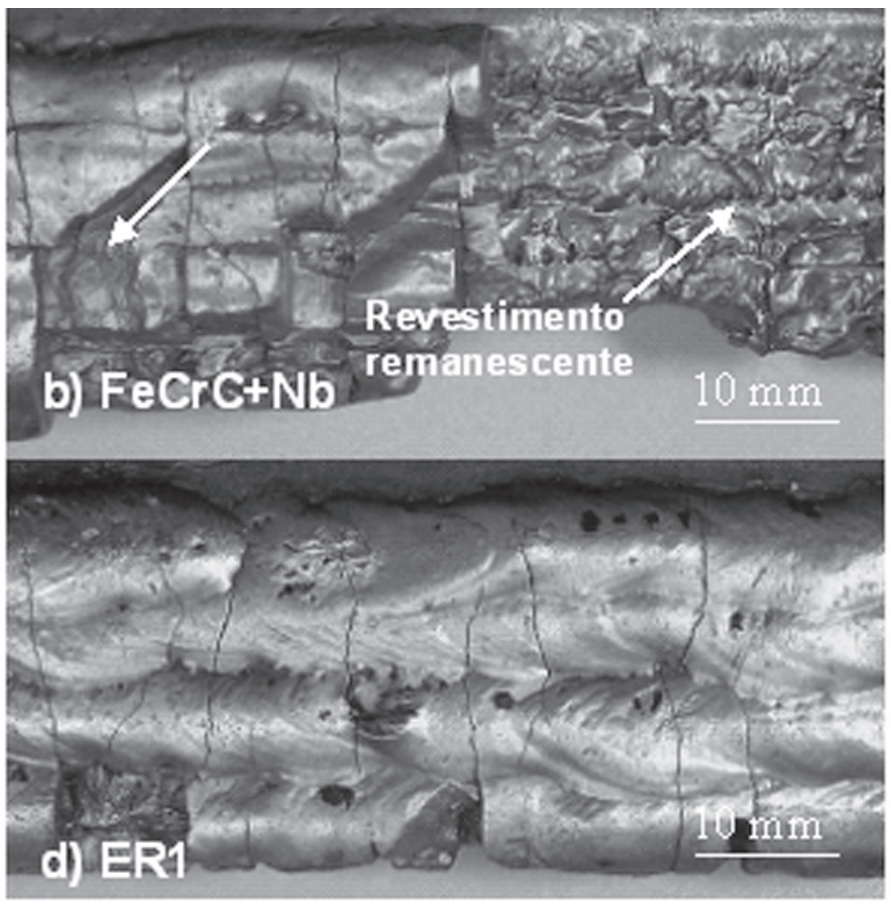

Figura 9 - Detalhes das facas após o desgaste do trabalho em campo.

consumível para se opor à ação abrasiva nos distintos sistemas tribológicos.

A Figura 10 apresenta comparativamente a resistência ao desgaste dos ensaios em laboratório com a obtida em campo, com as ferramentas operando em situação real de trabalho. Verificase, primeiramente, que a resistência ao desgaste do revestimento em laboratório (Roda de Borracha) foi inferior à resistência ao desgaste em campo, indicando maior severidade das condições de ensaio do primeiro. Esse fato pode ser explicado pelo elevado rigor das condições laboratoriais que garantia sempre abrasivo novo, com dimensão padronizada, além de pressão e alimentação constante na interface disco de borracha-peça. Por outro lado, a eventual presença de pedaços de pedra, ferro e outros materiais estranhos durante o trabalho das ferramentas no picador, como referido por Buchanan, Shipway e McCartney [12], leva a supor que esses elementos constituam exceção em um processo com lavagem da cana eficaz, e que o agente de maior relevância na ação abrasiva de desgaste seja realmente a cana (caule, casca, nós, bagaço, etc.), de inferiores propriedades abrasivas, além de resíduos de terra e areia remanescentes do processo de lavagem.

Observa-se ainda na Figura 10 para os arames tubulares, que excetuando-se o arame $+\mathrm{Nb}$ que apresentou a maior Rdesg em laboratório e a menor Rdesg em campo, os outros dois arames (FeCrC e + Ti) apresentaram comportamento similar. O arame $+\mathrm{Nb}$, devido ao excessivo lascamento, apresentou excessiva perda de metal em campo. Como discutido anteriormente, o melhor desempenho do arame $+\mathrm{Nb}$ em laboratório se deve à sua elevada resistência à abrasão, enquanto que o seu baixo desempenho em campo estaria relacionado à grande quantidade de trincas apresentada pelo revestimento.

Por sua vez, se comparado o eletrodo revestido ER1 com os arames tubulares, verifica-se que este apresentou resistência ao desgaste em laboratório similar ao arame de maior desempenho $(+\mathrm{Nb})$ e resistência ao desgaste em campo similar aos arames de maior desempenho ( $\mathrm{FeCrC} \mathrm{e}+\mathrm{Ti})$.

A divergência dos resultados em laboratório e em campo concorda com a afirmação de Eyre [13], segundo o qual é difícil predizer com um único ensaio o comportamento em serviço de 
um material, dada a multiplicidade de fatores que intervêm nos processos de desgaste, não sendo fácil encontrar um método de ensaio adequado a cada tribosistema.

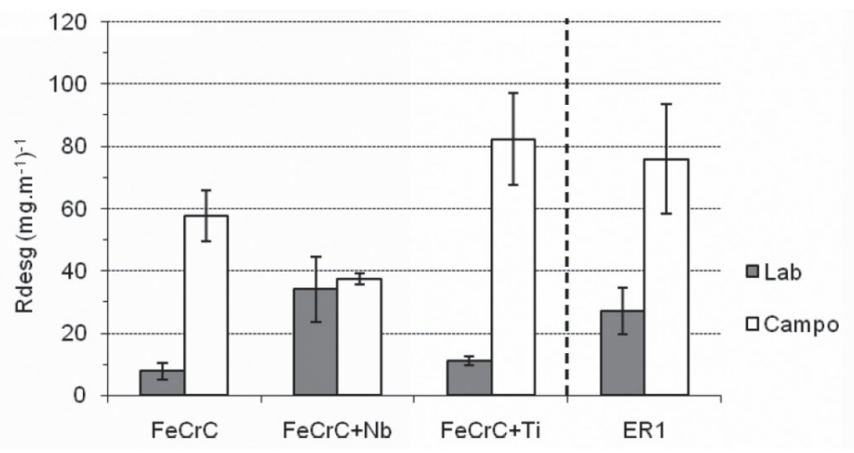

Figura 10 Comparação da resistência ao desgaste em laboratório "versus" campo

A diferença nos resultados dos ensaios em laboratório e em campo indica que o ensaio com o abrasômetro Roda de Borracha, nas condições realizadas, não tenha sido eficaz para simular com fidelidade o desgaste observado nas facas picadoras de cana-deaçúcar em situação real de trabalho. E que uma provável menor evidência de trincas do revestimento + Ti tenha sido o diferencial para o seu maior desempenho em campo na presença de impacto com a estrutura do picador, com a cana e outros materiais estranhos. Em função disso, acredita-se que um método de ensaio que combine abrasão e impacto seja mais representativo do mecanismo de desgaste das ferramentas durante a operação na indústria. Como nem sempre é possível realizar a avaliação de resistência dos revestimentos em situação real de trabalho e isso, quando possível se torna difícil e oneroso, acredita-se que a identificação de um método de ensaio que seja representativo do referido tribosistema, seja importante para avaliações futuras.

\section{Conclusões}

A análise dos resultados em laboratório com Roda de Borracha permite concluir que a liga contendo $+\mathrm{Nb}$ apresentou maior resistência ao desgaste abrasivo de baixa tensão em depósitos em camada única que as ligas com a adição de +Ti e a liga $\mathrm{FeCrC}$. A resistência ao desgaste do eletrodo revestido ficou um pouco abaixo do $+\mathrm{Nb}$.

A análise dos resultados em campo (condição real de trabalho) permite chegar às seguintes conclusões:

$\checkmark \quad$ A maior resistência ao desgaste em campo foi obtida pelas facas picadoras revestidas com o arame tubular $+\mathrm{Ti}$, seguida do $\mathrm{FeCrC}$ e do $+\mathrm{Nb}$. Apenas o revestimento $+\mathrm{Ti}$ apresentou desempenho superior ao eletrodo revestido ER1;

$\checkmark$ O lascamento do revestimento foi decisivo no mau desempenho do revestimento $+\mathrm{Nb}$ e parcialmente no revestimento $\mathrm{FeCrC}$, devido à formação e propagação de trincas de solidificação;

$\checkmark \quad$ A presença de descontinuidades como trincas podem favorecer o destacamento de partes do revestimento, aumentando a taxa de desgaste nas condições de campo;

$\checkmark \quad$ A ausência de trincas do revestimento +Ti deve ter sido o diferencial para o seu maior desempenho em campo na presença de impacto com a cana, a estrutura do picador e outros materiais estranhos. Opostamente, a maior quantidade de trincas (não quantificadas) do revestimento $+\mathrm{Nb}$ pode ter sido responsável pela sua maior perda de massa.

Quanto à comparação do desgaste em laboratório "versus" campos permite chegar às seguintes conclusões:

$\checkmark \quad$ Do ponto de vista da abrasão, o ensaio em campo foi menos severo que em laboratório, quando os arames tubulares de maior desempenho apresentaram resistência ao desgaste em torno de sete vezes superior;

$\checkmark \quad$ O maior desempenho em campo, das facas picadoras de cana-de-açúcar, é obtido com revestimentos que combinem maior resistência à abrasão com ausência ou menor quantidade de trincas;

$\checkmark \quad$ O ensaio por roda de borracha não reproduziu fielmente o sistema tribológico das facas picadoras de cana-de-açúcar em condição real de trabalho, pois não simula a ocorrência de impacto.

\section{Agradecimentos}

Os autores expressam o seu agradecimento às instituições que apoiaram para realização deste trabalho (CNPq, CAPES, FAPEMIG, IFG (Goiânia) e UFU).

\section{Referências Bibliográficas}

[1] JORNALCANA. Disponível em www.jornalcana.com.br. Acesso em: 25 de maio de 2008.

[2] ASTM. "Standard Test Method for Measuring Abrasion Using The Dry Sand/Rubber Wheel Aparatus". ASTM G65-91. 1991, p. 231-243.

[3] LIMA, A. C., e FERRARESI, V. A. Análise da Microestrutura e da Resistência ao Desgaste de Revestimento Duro Utilizado Pela Indústria Sucroalcooleira. Soldagem \& Inspeção, v. 14, 2009, p. 140/5-150.

[4] BUCHELY, M. F.; GUTIERREZ, J. C.; LEÓN, L. M. E TORO, A. The Effect of Microstructure on Abrasive Wear of Hardfacing Alloys. "Tribology International". Vol. 259, 2005, p. 52-61.

[5] CARCELlER, R. C. Influencia de los Parâmetros del Régimen de Recargue en la Morfología de los Depósitos de Acero e Fundición Blanca al Cromo y su incremento en la Resistencia al Desgaste Abrasivo. Instituto Superior Politécnico José Antonio Echeverría, Facultad de Ingeniería Mecánica, República de Cuba, Tesis de Doctorado en Ciencias Técnicas, 2007, 154p.

[6] GREGORY, E. N. Surfacing by Welding. The Welding Institute Research Bulletin. p. 9-13. jan. 1980.

[7] WANG, X. H.; ZOU, Z. D.; QU, S. Y. E SONG, S. L. Microstrutere and Wear propertiees of Fe-band Hardfacing Coating Reinforced by TiC Particles. Journal of materials processing Technology. P.3-6, nov. 2004.

[8] WAINER, E.; BRANDI, S. D.; DE MELLO, F. D. H. Soldagem - Processos e Metalurgia.Editora Edgard Blucher Ltda. 494 p. 1992. 
[9] SCOTTI, A. e ROSA, L. A. A. Influence of Oscillation Parameters on Crack Formation in Automatic Fe-B Hardfacing. Journal of Materials Processing Technology. p. 272-280, 1997.

[10] MARTINS FILHO, A. S. "Soldagem de Revestimentos com Arame Tubular". Universidade Federal de São Carlos. Dissertação de Mestrado. 1995, 93 p.

[11] CORRÊA, E. O.; ALCÂNTARA, N. G.; TECCO, D. G.; KUMMAR, R. V. Avaliação de Resistência ao Desgaste de Ligas $\mathrm{Fe}-\mathrm{Cr}-\mathrm{C}-\mathrm{Nb}-\mathrm{V}$ Desenvolvidas para a Solda de Revestimento Duro para Uso sob Condições Altamente Abrasivas. " 8 " Congreso Iberoamericano de Ingeniería Mecánica - CIBIM 8", Cusco, Peru, out. 2007.

[12] BUCHANAN, V. E; SHIPWAY, P. H.; MCCARTNEY, D. G. Microstructure and Abrasive Wear Behaviour of Shielded Metal Arc Welding Hardfacings Used in the Sugarcane Industry. Wear. p. 1 - 12, 2007.

[13] EYRE, T. S. Friction and Wear Mechanisms. ABM. II Seminário sobre Materiais Resistentes ao Desgaste. Uberlândia - MG. p. 263-306, dez. 1991. 